\title{
Risk Factors for Impaired Patient-Reported Satisfaction and Increased Length of Hospital Stay Following Hysterectomy on Benign Indications in Premenopausal Women: a Study From the Swedish National Register for Gynecological Surgery \\ Risikofaktoren für verminderte Patientinnenzufriedenheit und eine verlängerte Verweildauer im Krankenhaus bei prämenopausalen Frauen nach einer Hysterektomie wegen gutartiger Erkrankung: eine Studie aus dem schwedischen nationalen Register der gynäkologischen Chirurgie
}

\section{(ㄷ) (i) (오 $\Theta$}

Author

Ninnie Borendal Wodlin

\section{Affiliation}

Children and Women's Health, Department of Clinical and Experimental Medicine, Faculty of Medicine and Health Science, Linköping University, Linköping, Sweden

Key words

hysterectomy, complications, satisfaction, length of hospital stay

Schlüsselwörter

Hysterektomie, Komplikationen, Zufriedenheit, Verweildauer im Krankenhaus

received 14.4 .2019

revised 23.8.2019

accepted 28.8.2019

Bibliography

DOI https://doi.org/10.1055/a-1005-0039

Published online 23. 10. 2019 | Geburtsh Frauenheilk 2020; 80: 288-299 @ Georg Thieme Verlag KG Stuttgart .

New York | ISSN 0016-5751

Correspondence

Ninnie Borendal Wodlin, MD, PhD

Department of Obstetrics and Gynecology,

University Hospital

S-58185 Linköping, Sweden

Ninnie.Borendal.Wodlin@regionostergotland.se

\section{ABSTRACT}

Introduction The aims of the study were to evaluate the impact of intra- and postoperative complications on satisfaction one year after hysterectomy for benign conditions, to determine risk factors for low patient satisfaction and to analyze whether complications were associated with the length of hospital stay.

Material and Methods A retrospective study of 27938 women from the Swedish National Register for Gynecological Surgery undergoing hysterectomy for benign conditions between January 2004 and June 2016. Data were obtained from prospectively collected pre-, peri- and postoperative forms. Statistical analyses were performed using multivariable logistic regression models. Crude and adjusted odds ratios and 95\% confidence intervals are presented.

Results More than $90 \%$ were satisfied with the hysterectomy. Dissatisfaction was associated with complications. Pelvic pain as indication, preoperatively having less expectations to get rid of symptoms or being alleviated from surgery, and current smoking were also risk factors for low patient satisfaction. Vaginal and abdominal subtotal hysterectomies were associated with high satisfaction. Occurrence of complications intraand postoperatively before discharge was associated with increased length of hospital stay, as well as occurrence and severity of complications reported after discharge from hospital.

Conclusions Complications were strongly associated with lower patient satisfaction. Preoperative expectations of surgery, indication, mode of surgery and life-style factors had impact on the satisfaction. Patient-centered information to ensure realistic expectations and prevention of complications seem to be essential to gain optimal patient satisfaction with surgery. 


\section{ZUSAMMENFASSUNG}

Einleitung Ziel dieser Studie war es, die Auswirkungen intraoperativer und postoperativer Komplikationen auf die Patientinnenzufriedenheit 1 Jahr nach einer Hysterektomie wegen gutartiger Erkankung zu evaluieren und die Risikofaktoren für eine niedrige Zufriedenheit herauszuarbeiten. Es wurde auch geprüft, ob Komplikationen mit der Länge der Verweildauer im Krankenhaus zusammenhingen.

Material und Methoden Es wurde eine retrospektive Studie von 27938 im schwedischen nationalen Register der gynäkologischen Chirurgie aufgeführten Frauen durchgeführt, die sich zwischen Januar 2004 und Juni 2016 einer Hysterektomie wegen gutartiger Erkrankung unterzogen hatten. Die Daten wurden Formularen entnommen, die vor, während und nach der Operation prospektiv Daten sammelten. Statistische Analysen wurden mithilfe der multivariablen logistischen Regression durchgeführt. Die rohen und adjustierten Odds-Ratios sowie die 95\%-Konfidenzintervalle wurden kalkuliert.

Ergebnisse Mehr als 90\% der Frauen waren mit der Hysterektomie zufrieden. Unzufriedenheit war mit dem Auftreten von Komplikationen assoziiert. Die Indikation „Becken- schmerzen“, eine niedrige Erwartung vor der Operation, dass Symptome nach der Operation gemildert oder verschwinden würden, und Rauchen waren alles Risikofaktoren für eine niedrige Patientinnenzufriedenheit. Vaginale und abdominale subtotale Hysterektomien waren mit einer hohen Zufriedenheitsrate assoziiert. Das Auftreten von intraoperativen und postoperativen Komplikationen noch vor der Entlassung aus dem Krankenhaus war mit einer längeren Verweildauer im Krankenhaus sowie mit dem Auftreten von Komplikationen nach der Entlassung und schwereren Komplikationen assoziiert.

Schlussfolgerungen Komplikationen waren eng mit niedrigerer Patientinnenzufriedenheit assoziiert. Die präoperativen Erwartungen an das Outcome der Operation, die Indikation, die Art des Eingriffs und Lebensstilfaktoren wirkten sich auf die Patientinnenzufriedenheit aus. Die an Patientinnen gerichteten Informationen müssen patientenzentriert sein, um sicherzustellen, dass die Erwartungen der Patientinnen realistisch sind, und um Komplikationen zu vermeiden und dadurch eine optimale Patientinnenzufriedenheit mit der Operation zu erzielen.

$\begin{array}{ll}\text { Abbreviations } \\ \text { aOR } & \begin{array}{l}\text { adjusted odds ratio } \\ \text { the American Society of Anesthesiologists' } \\ \text { ASA }\end{array} \\ \text { BMI } & \begin{array}{l}\text { body masication of physical status } \\ \text { cl }\end{array} \\ \text { GynOp } & \begin{array}{l}\text { confidence interval } \\ \text { the Swedish National Register for Gynecological }\end{array} \\ \text { LOS } & \begin{array}{l}\text { Surgery } \\ \text { length of hospital stay } \\ \text { OR }\end{array} \\ \text { SD } & \begin{array}{l}\text { odds ratio } \\ \text { standard deviation }\end{array}\end{array}$

\section{Introduction}

Hysterectomy performed on benign indication is the most common major gynecological procedure [1]. Hysterectomy may be accomplished either by removing the entire uterus (total hysterectomy) or retaining the cervical part (subtotal hysterectomy) using an abdominal or minimally invasive (laparoscopic or vaginal) approach [2].

More than $90 \%$ of women report a high satisfaction rate several years following hysterectomy, irrespective of surgical approach or technique $[1,3,4]$. High levels of satisfaction are correlated with improvements in symptoms, such as abnormal uterine bleeding or mechanical symptoms of myoma. Pelvic pain or endometriosis as indication of hysterectomy can be associated with greater dissatisfaction of the result of surgery [5].

However, risk factors for an adverse outcome following hysterectomy in patient-reported measures have rarely been reported in the literature. It seems crucial to focus on achievement of the goals of surgery in a patient perspective, to gain a more patientcentered health care. Moreover, the association between the ap- pearance and degree of intra- and postoperative complications following hysterectomy and the perceived satisfaction rate has not been particularly studied [5-7].

Intra- and postoperative complications may occur whatever surgical technique or approach is used, although complications seem less frequent following minimally invasive surgery (around $10 \%$ for vaginal hysterectomy, up to $20 \%$ reported for abdominal hysterectomy) $[3,4]$. It seems reasonable to believe that adverse events associated with hysterectomy could affect the woman's satisfaction with the result of surgery.

The aim of this retrospective register study was to evaluate the impact of intra- and postoperative complications on the perceived satisfaction and self-reported assessment of the medical condition one year after hysterectomy on benign indications, and to determine risk factors for adverse outcomes in these measures. A secondary aim was to analyze whether complications occurring at different times during and after the hospital stay were associated with the length of hospital stay (LOS).

\section{Material and Methods}

\section{Study design}

This study consists of retrospective data from the Swedish National Register for Gynecological Surgery (GynOp) [8], on the cohort of women undergoing hysterectomy for benign conditions between January 2004 and June 2016. Exclusion criteria were postmenopausal women or women more than 55 years of age, present adnexal tumor, dysplasia, prolapse or urinary incontinence as main indication for surgery, indication or mode of surgery unclear, preventive or pregnancy-related surgery, and present chronic infectious diseases. More than $75 \%$ of women 


\section{Preoperative questionnaire}

Q: What are your expectations of the surgery?

A: $\square$ No expectations $\square$ Symptoms to be relieved $\square$ Get rid of symptoms

\section{Eight-week questionnaire}

Q: Have you experienced any unexpected complications related to the surgery?

A: $\square$ No $\square$ Yes, mild $\square$ Yes, severe $\square$ Yes, both mild and severe

Q: How do you rate the results of the surgery so far?

A: My medical condition is:

$\square$ Much improved $\square$ Improved $\square$ Unchanged $\square$ Worse $\square$ Much worse

\section{One-year questionnaire}

Q: During the period from two months after the surgery until today have you had any complications related to the surgery?

A: $\square$ No $\square$ Yes, mild $\square$ Yes, severe

Q: How do you rate your medical condition at present?

A: $\square$ Much improved $\square$ Improved $\square$ Unchanged $\square$ Worse $\square$ Much worse

Q: Regarding the result of the operation?

A: $\square$ Very satisfied $\square$ Satisfied $\square$ Neither-nor $\square$ Dissatisfied $\square$ Very dissatisfied

Fig. 1 Questions (Q) and options for possible answers (A) in the inquiry forms from the GynOp.

undergoing hysterectomy on benign indications participate in the GynOp [8].

All women received written information about the register before surgery, and could decline to participate if desired. Both women and physicians were involved in the data collection process. The women completed a health declaration form and answered questions about subjective symptoms preoperatively. Preoperative expectation of surgery was asked for and the women had three alternative answers to the question: Get rid of symptoms, Be relieved of symptoms or No expectations of surgery. The gynecologist who performed the preoperative assessment completed a form about preoperative objective findings. The surgeon recorded information about surgery in connection with the operation. The gynecologist filled out a postoperative form concerning the postoperative course at discharge. The day of surgery and discharge from hospital were registered, which enabled calculation of LOS.

Eight weeks and one year postoperatively the women received an inquiry questionnaire regarding health status, opinions covering recovery and experiences of surgery, any adverse advents, satisfaction with surgery, and their current medical condition in relation to outcome of surgery. In addition, the gynecologist reviewed and evaluated all inquiry forms to obtain the most correct data [8]. All information from the women and the gynecologist's evaluation were recorded in the register.

\section{Data collection}

Assembled data included:

1. demographics from health declaration form: age, parity, height and weight, (enables calculation of body mass index $[\mathrm{BMI}])$, smoking habits, and women's preoperative expectations of surgery;

2. clinical data accumulated peri- and postoperatively: the American Society of Anesthesiologists' classification (ASA), main indications of surgery categorized in four groups (menstrual disorder, uterine myoma, pain-related or other indications (premenstrual tension syndrome, hormone therapy related problems other than bleeding disorder, cervical stenosis and hematometra, chronic cervicitis, complications with intrauterine device, and urinary dysfunction related to the uterus), surgical technique (subtotal/total) and approach (at conclusion of surgery, that is abdominal or minimally invasive [laparoscopic or vaginal]), whether the woman had any remaining ovary at conclusion of surgery, complications during hospital stay;

3. from the eight-week inquiry form: occurrence of complications after discharge, and

4. information from the one-year inquiry form covering questions about occurrence of complications from eight weeks postoperatively up to one year, and rating of medical condition at present, and contentment with the result of surgery. The questions (Q) and options for possible answers (A) in the inquiry forms are presented in $>$ Fig. 1. 


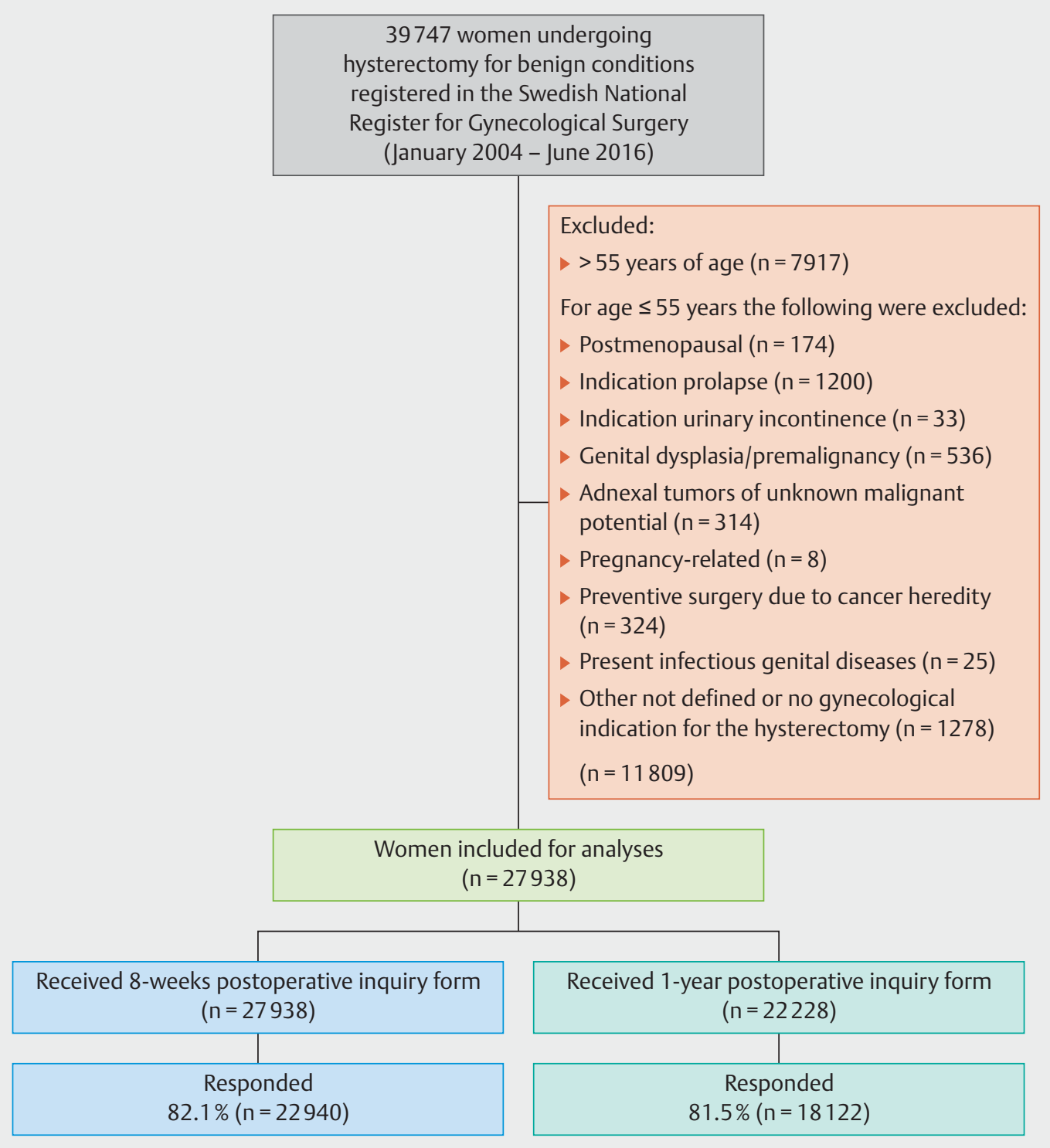

- Fig. 2 Flow chart demonstrating the selection of the study population of women undergoing hysterectomy.

\section{Missing data}

The women who underwent surgery less than one year prior to the data retrieval did not have the possibility to answer the oneyear questionnaires. Moreover, some of the questions in the inquiries have changed over time. Thus, there will be missing data for some of the items. The question in the preoperative inquiry form concerning the patient's expectation of the surgery (get rid of the symptoms; be relieved, or do not have expectations) was excluded in 2013 and the one-year inquiry form concerning medical condition was included 2007 and concerning result of surgery in 2010. The one-year inquiry questionnaire was optional. All except one region in Sweden systematically sent the form to all participating women. The response rate of the one-year inquiry form was consequently determined as the proportion of women answering the inquiry form of those who de facto received the form.

\section{Classification of complications}

The GynOp has classified complications as mild or severe. Severe complications, which are equivalent to major complications, were defined as thromboembolism, all injuries to the bladder, ureter, bowel, or major vascular structures, fistula, bleeding of more than $3000 \mathrm{ml}$, any reason making a re-operation necessary, hospitalization for more than seven days, persistent physical handicap or death of the patient. Furthermore, septic postoperative infections, and any other major complication (i.e. aspiration, allergic shock, myocardial infarct, or cerebral complication) also constitute severe complications [9]. Mild complications are equivalent to minor complications, and were defined as adverse events that did not have the severity of major complications for example urinary tract infections and wound complications/infections. 


\section{Statistical analyses}

The software Statistica v 13.2 (Dell Software, 5 Polaris Way, Aliso Viejo, CA 92656, USA) was used for the statistical analyses.

Data are presented as mean and one standard deviation (SD) or number and per cent. Continuous data were analyzed by means of one-way ANOVA or Student's t-test, and categorical data by means of $X^{2}$ test for trends. Analyses of LOS in relation to complications were performed by means of ANCOVA models adjusted for BMI, smoking habits, and occurrence of complications developed prior to the occasion of evaluation. Post hoc tests were evaluated by means of Tukey's honest significant difference tests.

In order to assess the impact of various factors on outcome measures of PREM and PROM, multivariable logistic regression models were assessed. The dependent variable medical condition was dichotomized in "improved or much improved" versus "unchanged, worse or much worse". Likewise was the opinion about the result of the surgery one year postoperatively dichotomized in "satisfied or very satisfied" versus "neither satisfied nor dissatisfied”. Multivariable logistic regression models were adjusted for known or potential confounding factors. The confounding factors (age, BMI [as a continuous variable], smoking, indication and mode of hysterectomy and having a remaining ovary postoperatively) were entered simultaneously into the models. Results are presented as crude and adjusted odds ratios (ORs or aORs) and $95 \%$ confidence intervals $(\mathrm{Cl})$. The significance level was set at $\mathrm{p}<0.05$.

\section{Ethical approval}

The study was approved by the Regional Ethics Board of Linköping University (Reg. nr. M19-07; amendment 2016/66-32).

\section{Results}

\section{Study population}

- Fig. 2 presents a flow chart of the study population.

Demographic, descriptive and clinical characteristics subdivided according to mode of surgery at conclusion of the operation are demonstrated in $>$ Table 1 . The number of missing data is presented in $\mathbf{r}$ Tables $\mathbf{2}$ and $\mathbf{3}$ in connection with each variable and varies from a few per cent to a larger proportion; in the latter case mostly due to the limitation in use over time of the item in the inquiry forms. Five hundred and thirty-six of those who were originally scheduled for a minimally invasive procedure, 282 (4.4\%) laparoscopically and 254 (7.1\%) vaginally, were intraoperatively converted to abdominal hysterectomy.

- Table 1 Demographic, descriptive and clinical data of 27938 women undergoing hysterectomy for benign conditions in relation to mode of surgery (at conclusion of the operation).

\begin{tabular}{|c|c|c|c|c|c|}
\hline \multirow{3}{*}{ Characteristics } & \multicolumn{2}{|l|}{ By laparotomy } & \multicolumn{3}{|c|}{ By minimally invasive technique } \\
\hline & \multirow[t]{2}{*}{$\begin{array}{l}\text { Total hysterectomy } \\
n=13709 \text { (49.1\%) }\end{array}$} & \multirow{2}{*}{$\begin{array}{l}\text { Subtotal } \\
\text { hysterectomy } \\
n=4774(17.1 \%)\end{array}$} & \multicolumn{2}{|c|}{$\begin{array}{l}\text { Laparoscopic hysterectomy } \\
n=3337(11.9 \%)\end{array}$} & \multirow{2}{*}{$\begin{array}{l}\text { Vaginal } \\
\text { hysterectomy } \\
n=6118(21.9 \%)\end{array}$} \\
\hline & & & $\begin{array}{l}\text { Total hysterectomy } \\
\mathrm{n}=\mathbf{2 8 7 8}(\mathbf{1 0 . 3} \%)\end{array}$ & $\begin{array}{l}\text { Subtotal } \\
\text { hysterectomy } \\
n=459(1.6 \%)\end{array}$ & \\
\hline Age (years) & $45.6(5.1)$ & $45.5(5.0)$ & $44.6(5.4)$ & $45.1(4.9)$ & $44.4(5.1)$ \\
\hline BMI $\left(\mathrm{kg} / \mathrm{m}^{2}\right)$ & $26.4(4.6)$ & $26.8(5.0)$ & $26.1(4.7)$ & $25.2(4.4)$ & $26.1(4.7)$ \\
\hline Parity & $2.1(1.2)$ & $2.1(1.2)$ & $2.1(1.2)$ & $1.9(1.1)$ & $2.5(1.1)$ \\
\hline \multicolumn{6}{|c|}{ Smoking (no. of women): } \\
\hline - Yes & $1991(14.5 \%)$ & $686(14.4 \%)$ & $357(12.4 \%)$ & $33(7.2 \%)$ & $1011(16.5 \%)$ \\
\hline - No & $8833(64.4 \%)$ & $3316(69.4 \%)$ & $1594(55.4 \%)$ & $154(33.5 \%)$ & $3595(58.8 \%)$ \\
\hline - Missing data & $2885(21.1 \%)$ & $772(16.2 \%)$ & $927(32.2 \%)$ & $272(59.3 \%)$ & $1512(24.7 \%)$ \\
\hline \multicolumn{6}{|c|}{ Indication of hysterectomy: } \\
\hline - Menstrual disorder & $7737(56.4 \%)$ & $2978(62.4 \%)$ & $1560(54.2 \%)$ & $147(32.0 \%)$ & $4352(71.1 \%)$ \\
\hline - Uterine myoma & $2522(18.4 \%)$ & $717(15.0 \%)$ & $146(5.1 \%)$ & $18(3.9 \%)$ & $174(2.8 \%)$ \\
\hline - Pain-related* & $1542(11.3 \%)$ & $481(10.1 \%)$ & $499(17.3 \%)$ & $33(7.2 \%)$ & $498(8.1 \%)$ \\
\hline - Other indications & $130(0.9 \%)$ & $48(1.0 \%)$ & $36(1.3 \%)$ & $0(0 \%)$ & $10(0.2 \%)$ \\
\hline - Missing data & $1778(13.0 \%)$ & $550(11.5 \%)$ & $637(22.1 \%)$ & 261 (56.9\%) & $1084(17.7 \%)$ \\
\hline \multicolumn{6}{|l|}{ ASA: } \\
\hline - Class I/II & 13197 (96.3\%) & 4600 (96.4\%) & 2779 (96.6\%) & $450(98.0 \%)$ & 5965 (97.5\%) \\
\hline - Class III/IV & $208(1.5 \%)$ & $67(1.4 \%)$ & $49(1.7 \%)$ & $4(0.9 \%)$ & $52(0.8 \%)$ \\
\hline - Missing data & $304(2.2 \%)$ & $107(2.2 \%)$ & $50(1.7 \%)$ & $5(1.1 \%)$ & $101(1.7 \%)$ \\
\hline Operating time (min) & $100(41)$ & $83(35)$ & $116(47)$ & $96(43)$ & $66(31)$ \\
\hline Uterus weight (g) & $533(523)$ & $487(436)$ & $229(146)$ & $243(174)$ & $192(123)$ \\
\hline
\end{tabular}


- Table 1 Demographic, descriptive and clinical data of 27938 women undergoing hysterectomy for benign conditions in relation to mode of surgery (at conclusion of the operation). (Continued)

\begin{tabular}{|c|c|c|c|c|c|}
\hline \multirow{3}{*}{ Characteristics } & \multicolumn{2}{|l|}{ By laparotomy } & \multicolumn{3}{|c|}{ By minimally invasive technique } \\
\hline & \multirow[t]{2}{*}{$\begin{array}{l}\text { Total hysterectomy } \\
n=13709 \text { (49.1\%) }\end{array}$} & \multirow{2}{*}{$\begin{array}{l}\text { Subtotal } \\
\text { hysterectomy } \\
n=4774(17.1 \%)\end{array}$} & \multicolumn{2}{|c|}{$\begin{array}{l}\text { Laparoscopic hysterectomy } \\
\mathrm{n}=3337(11.9 \%)\end{array}$} & \multirow{2}{*}{$\begin{array}{l}\text { Vaginal } \\
\text { hysterectomy } \\
n=6118(21.9 \%)\end{array}$} \\
\hline & & & $\begin{array}{l}\text { Total hysterectomy } \\
n=2878(10.3 \%)\end{array}$ & $\begin{array}{l}\text { Subtotal } \\
\text { hysterectomy } \\
n=459(1.6 \%)\end{array}$ & \\
\hline $\begin{array}{l}\text { Estimated perioperative bleeding } \\
\text { volume }(\mathrm{ml})\end{array}$ & $327(349)$ & $273(307)$ & $132(162)$ & $127(135)$ & $137(147)$ \\
\hline \multicolumn{6}{|l|}{$\begin{array}{l}\text { Remaining at least one ovary } \\
\text { postoperatively: }\end{array}$} \\
\hline - Yes & $11136(81.2 \%)$ & $4125(86.4 \%)$ & $2032(70.6 \%)$ & $199(43.4 \%)$ & $4770(78.0 \%)$ \\
\hline - No & $1012(7.4 \%)$ & $167(3.5 \%)$ & $258(9.0 \%)$ & $3(0.6 \%)$ & $29(0.5 \%)$ \\
\hline - Missing data & $1561(11.4 \%)$ & $482(10.1 \%)$ & $588(20.4 \%)$ & $257(56.0 \%)$ & $1319(21.5 \%)$ \\
\hline \multicolumn{6}{|l|}{ Preoperative expectation of surgery: } \\
\hline - Get rid of symptoms & $4871(35.5 \%)$ & $2188(45.8 \%)$ & $387(13.5 \%)$ & $104(22.7 \%)$ & $2276(37.2 \%)$ \\
\hline - Relieved & $1462(10.7 \%)$ & $629(13.2 \%)$ & $166(5.8 \%)$ & $29(6.3 \%)$ & $592(9.7 \%)$ \\
\hline - None & $200(1.5 \%)$ & $64(1.3 \%)$ & $13(0.4 \%)$ & $1(0.2 \%)$ & $42(0.7 \%)$ \\
\hline - Missing data ${ }^{\S}$ & $7176(52.3 \%)$ & $1893(39.7 \%)$ & $2312(80.3 \%)$ & $325(70.8 \%)$ & $3208(52.4 \%)$ \\
\hline
\end{tabular}

\section{Complications}

Prevalence and degree of severity of complications in relation to the occasion of reporting the complication and to modes of hysterectomy are shown in - Table 2 . In total, 67.9\% (11132/16388) reported a completely complication-free hysterectomy within the first year postoperatively.

- Table 3 shows the self-reported perception of medical condition and opinion of result of surgery one year postoperatively in relation to reported complications and severity intra- and postoperatively. The women with a complication-free hysterectomy reported an improved medical condition and satisfaction with the hysterectomy in $95-97 \%$ and $93-95 \%$, respectively, but the prevalence decreased to 80 and $60 \%$, respectively when major complications had occurred.

The associations between complications and patient satisfaction reported one year postoperatively are shown in $\mathbf{~ T a b l e ~} \mathbf{4}$. When adjusted for confounding factors, medical condition after one year was strongly negatively associated with complications of all grades occurring after discharge from hospital. Except for minor complications occurring intraoperatively, the reported satisfaction with hysterectomy one year after surgery was strongly negatively associated with all grades of severity of complications on all occasions. In particular, major complications reported at the one-year inquiry were highly associated with dissatisfaction with the result of surgery.

\section{Unfavorable outcomes}

- Table 5 shows various predictive factors for unfavorable outcome of surgery reported one year postoperatively. In the adjusted models, the perceived medical condition was significantly adversely associated with having no preoperative expectation of surgery (aOR 4.85 [95\% Cl 2.80-8.40]), smoking (aOR 1.45 [95\% Cl 1.14-1.84]), having uterine myoma (aOR 2.33 [95\% Cl 1.822.98]), or pain-related (aOR 3.29 [95\% Cl 2.57-4.22]) as indications for hysterectomy. Of the mode of hysterectomy only vaginal hysterectomy was significantly positively associated with the medical condition reported at the one-year inquiry (aOR 0.64 [95\% Cl 0.47-0.87]). Furthermore, vaginal and subtotal abdominal hysterectomies were independent predictive factors for higher satisfaction after surgery (aOR 0.61 [95\% $\mathrm{Cl} 0.51-0.71]$ and $\mathrm{aOR}$ 0.74 [95\% Cl 0.62-0.87], respectively). Pain as indication of surgery was a strong risk factor for experienced dissatisfaction (aOR 2.17 [95\% Cl 1.85-2.55]). Likewise, smoking and having no preoperative expectations of surgery or believing that the only benefit of surgery would be alleviated of symptoms and being without ovaries after the surgery were independently associated with dissatisfaction. Intraoperative conversion of a minimally invasive procedure to laparotomy did not seem to affect the reported medical condition or satisfaction with the surgery one year after the operation. 
- Table 2 Occurrence and classification of complications intra- and postoperatively after hysterectomy in relation to surgical mode.

\begin{tabular}{|c|c|c|c|c|c|}
\hline \multirow{3}{*}{ Complications reported } & \multicolumn{2}{|l|}{ By laparotomy } & \multicolumn{3}{|c|}{ By minimally invasive technique } \\
\hline & \multirow[t]{2}{*}{$\begin{array}{l}\text { Total hysterectomy } \\
n=13709 \text { (49.1\%) }\end{array}$} & \multirow{2}{*}{$\begin{array}{l}\text { Subtotal } \\
\text { hysterectomy } \\
n=4774(17.1 \%)\end{array}$} & \multicolumn{2}{|c|}{$\begin{array}{l}\text { Laparoscopic hysterectomy } \\
n=3337(11.9 \%)\end{array}$} & \multirow{2}{*}{$\begin{array}{l}\text { Vaginal } \\
\text { hysterectomy } \\
n=6118(21.9 \%)\end{array}$} \\
\hline & & & $\begin{array}{l}\text { Total hysterectomy } \\
n=2878(10.3 \%)\end{array}$ & $\begin{array}{l}\text { Subtotal } \\
\text { hysterectomy } \\
n=459(1.6 \%)\end{array}$ & \\
\hline \multicolumn{6}{|l|}{ Intraoperatively: } \\
\hline - None & $12982(94.7 \%)$ & 4589 (96.1\%) & 2790 (96.9\%) & $452(98.5 \%)$ & 5937 (97.0\%) \\
\hline - Minor & $532(3.9 \%)$ & $148(3.1 \%)$ & $60(2.1 \%)$ & $6(1.3 \%)$ & $136(2.2 \%)$ \\
\hline - Major & $173(1.3 \%)$ & $35(0.7 \%)$ & $13(0.5 \%)$ & $1(0.2 \%)$ & $30(0.5 \%)$ \\
\hline - Missing & $22(1.1 \%)$ & $2(0.1 \%)$ & $15(0.5 \%)$ & $0(0.0 \%)$ & $15(0.3 \%)$ \\
\hline \multicolumn{6}{|c|}{ After surgery, during hospital stay: } \\
\hline - None & $12178(88.8 \%)$ & $4312(90.3 \%)$ & $2676(93.0 \%)$ & $441(96.1 \%)$ & $5635(92.1 \%)$ \\
\hline - Minor & $985(7.2 \%)$ & $310(6.5 \%)$ & $136(4.7 \%)$ & $12(2.6 \%)$ & $303(4.9 \%)$ \\
\hline - Major & $332(2.4 \%)$ & $85(1.8 \%)$ & $41(1.4 \%)$ & $5(1.1 \%)$ & $132(2.2 \%)$ \\
\hline - Missing & $214(1.6 \%)$ & $67(1.4 \%)$ & $25(0.9 \%)$ & $1(0.2 \%)$ & $48(0.8 \%)$ \\
\hline \multicolumn{6}{|c|}{ Within eight weeks after discharge: } \\
\hline - None & $8326(60.7 \%)$ & $3286(68.8 \%)$ & $1695(58.9 \%)$ & $244(53.2 \%)$ & $4096(67.0 \%)$ \\
\hline - Minor & $2474(18.0 \%)$ & $651(13.6 \%)$ & 385 (13.4\%) & $38(8.3 \%)$ & 783 (12.8\%) \\
\hline - Major & $460(3.4 \%)$ & $84(1.8 \%)$ & $90(3.1 \%)$ & $6(1.3 \%)$ & $179(2.9 \%)$ \\
\hline - Missing & $2449(17.9 \%)$ & $753(15.8 \%)$ & $708(24.6 \%)$ & $171(37.2 \%)$ & $1060(17.3 \%)$ \\
\hline \multicolumn{6}{|c|}{ Between eight weeks and one year: } \\
\hline - None & 7607 (55.5\%) & 3044 (63.8\%) & 1147 (39.9\%) & $159(34.6 \%)$ & 3639 (59.5\%) \\
\hline - Minor & $1097(8.0 \%)$ & $313(6.5 \%)$ & $128(4.4 \%)$ & $10(2.2 \%)$ & $286(4.7 \%)$ \\
\hline - Major & $229(1.7 \%)$ & $41(0.9 \%)$ & $34(1.2 \%)$ & $2(0.4 \%)$ & $68(1.1 \%)$ \\
\hline - Missing ${ }^{\S}$ & $4776(34.8 \%)$ & $1376(28.8 \%)$ & 1569 (54.5\%) & $288(62.8 \%)$ & 2125 (34.7\%) \\
\hline
\end{tabular}

Figures denote number of women and percent.

$\S$ Missing data are indicated for the entire group. Only $80 \%$ received the 1 -year postoperative inquiry form; consequently the missing data will constitute a high proportion.

- Table 3 Complications intra- and postoperatively after hysterectomy on various occasions until one year postoperatively in relation to dichotomized self-reported perception of medical condition/result of surgery.

\begin{tabular}{|c|c|c|c|c|}
\hline & \multicolumn{2}{|l|}{ Medical condition } & \multicolumn{2}{|c|}{ Result of surgery } \\
\hline & \multicolumn{2}{|c|}{ Received the specific question ( $n=20301$ ) } & \multicolumn{2}{|c|}{ Received the specific question ( $n=24443$ ) } \\
\hline & \multicolumn{2}{|c|}{ Reported $^{\S}(n=12506[61.6 \%])$} & \multicolumn{2}{|c|}{ Reported $^{\S}(n=17714[72.5 \%])$} \\
\hline Occasion of report/complication grade & $\begin{array}{l}\text { Improved or } \\
\text { much improved }\end{array}$ & $\begin{array}{l}\text { Unchanged, worse } \\
\text { or much worse }\end{array}$ & $\begin{array}{l}\text { Satisfied or } \\
\text { very satisfied }\end{array}$ & $\begin{array}{l}\text { Neither satisfied or } \\
\text { dissatisfied }\end{array}$ \\
\hline \multicolumn{5}{|l|}{ Intraoperatively: } \\
\hline - None & $11542(95.6 \%)$ & $529(4.4 \%)$ & 15717 (92.7\%) & $1236(7.3 \%)$ \\
\hline - Minor & $308(96.0 \%)$ & $13(4.0 \%)$ & $537(91.3 \%)$ & $51(8.7 \%)$ \\
\hline - Major & $94(95.0 \%)$ & $5(5.0 \%)$ & $111(81.0 \%)$ & $26(19.0 \%)$ \\
\hline - Missing data ${ }^{\#}$ & $13(86.7 \%)$ & $2(13.3 \%)$ & $33(91.6 \%)$ & $3(8.4 \%)$ \\
\hline \multicolumn{5}{|l|}{ After surgery, during hospital stay: } \\
\hline - None & $10837(95.8 \%)$ & $475(4.2 \%)$ & $14798(93.1 \%)$ & $1100(6.9 \%)$ \\
\hline - Minor & $734(93.6 \%)$ & $50(6.4 \%)$ & $1077(89.2 \%)$ & $130(10.8 \%)$ \\
\hline - Major & $227(93.8 \%)$ & $15(6.2 \%)$ & $286(80.5 \%)$ & $69(19.5 \%)$ \\
\hline - Missing data ${ }^{\#}$ & $159(94.6 \%)$ & $9(5.4 \%)$ & $237(93.3 \%)$ & $17(6.7 \%)$ \\
\hline
\end{tabular}


- Table 3 Complications intra- and postoperatively after hysterectomy on various occasions until one year postoperatively in relation to dichotomized self-reported perception of medical condition/result of surgery. (Continued)

\begin{tabular}{|c|c|c|c|c|}
\hline & \multicolumn{2}{|l|}{ Medical condition } & \multicolumn{2}{|c|}{ Result of surgery } \\
\hline & \multicolumn{2}{|c|}{ Received the specific question $(n=20301)$} & \multicolumn{2}{|c|}{ Received the specific question $(n=24443$ ) } \\
\hline & \multicolumn{2}{|c|}{ Reported $(n=12506[61.6 \%])$} & \multicolumn{2}{|c|}{ Reported $^{\S}(n=17714$ [72.5\%]) } \\
\hline Occasion of report/complication grade & $\begin{array}{l}\text { Improved or } \\
\text { much improved }\end{array}$ & $\begin{array}{l}\text { Unchanged, worse } \\
\text { or much worse }\end{array}$ & $\begin{array}{l}\text { Satisfied or } \\
\text { very satisfied }\end{array}$ & $\begin{array}{l}\text { Neither satisfied or } \\
\text { dissatisfied }\end{array}$ \\
\hline \multicolumn{5}{|l|}{ 8-weeks questionnaire: } \\
\hline - None & 8851 (96.7\%) & $301(3.3 \%)$ & 12077 (94.6\%) & $687(5.4 \%)$ \\
\hline - Minor & $2020(93.0 \%)$ & $151(7.0 \%)$ & $2780(88.2 \%)$ & $371(11.8 \%)$ \\
\hline - Major & $325(87.8 \%)$ & $45(12.2 \%)$ & $41376.6 \%)$ & $126(23.4 \%)$ \\
\hline - Missing data & $761(93.6 \%)$ & $52(6.4 \%)$ & $1128(89.5 \%)$ & $132(10.4 \%)$ \\
\hline \multicolumn{5}{|l|}{ 1-year questionnaire: } \\
\hline - None & $10192(96.8 \%)$ & $337(3.2 \%)$ & $14166(94.9 \%)$ & $755(5.1 \%)$ \\
\hline - Minor & $1046(90.4 \%)$ & $111(9.6 \%)$ & $1354(80.6 \%)$ & $327(19.4 \%)$ \\
\hline - Major & $169(80.1 \%)$ & $42(19.9 \%)$ & $201(60.5 \%)$ & $131(39.5 \%)$ \\
\hline - Missing data & $550(90.3 \%)$ & $59(9.2 \%)$ & $677(86.8 \%)$ & $103(13.2 \%)$ \\
\hline
\end{tabular}

Figures denote number of women and percent.

\# Data about complication or grade of complication not stated in the register at discharge from the hospital after surgery.

$\S$ The number of participants who have completed the one-year follow-up questionnaire or the specific question in the form.

- Table 4 Associations between complications and the dichotomized self-reported perception of medical condition and satisfaction on various occasions until one year postoperatively.

\begin{tabular}{|c|c|c|c|c|}
\hline \multirow[b]{2}{*}{ Factor } & \multicolumn{2}{|c|}{$\begin{array}{l}\text { Medical condition one year postoperatively: } \\
\text { Unchanged, worse or much worse }\end{array}$} & \multicolumn{2}{|c|}{$\begin{array}{l}\text { Opinion about the result of the surgery } \\
\text { one year postoperatively: } \\
\text { Neither satisfied or dissatisfied }\end{array}$} \\
\hline & $\begin{array}{l}\text { Crude OR and } \\
95 \% \mathrm{Cl}\end{array}$ & $\begin{array}{l}\text { Adjusted } \mathrm{OR} \\
\text { and } 95 \% \mathrm{Cl}^{*}\end{array}$ & $\begin{array}{l}\text { Crude OR and } \\
95 \% \mathrm{Cl}\end{array}$ & $\begin{array}{l}\text { Adjusted OR and } \\
95 \% \mathrm{Cl}^{*}\end{array}$ \\
\hline \multicolumn{5}{|c|}{ Intraoperative complications: } \\
\hline - None & 1.00 (reference) & 1.00 (reference) & 1.00 (reference) & 1.00 (reference) \\
\hline - Minor & $0.92(0.53-1.62)$ & $0.97(0.54-1.76)$ & $1.21(0.90-1.62)$ & $1.23(0.90-1.68)$ \\
\hline - Major & $1.16(0.47-2.87)$ & $0.86(0.27-2.76)$ & $2.98(1.94-4.58)$ & $2.79(1.74-4.46)$ \\
\hline \multicolumn{5}{|c|}{ Complications during hospital stay: } \\
\hline - None & 1.00 (reference) & 1.00 (reference) & 1.00 (reference) & 1.00 (reference) \\
\hline - Minor & $1.55(1.15-2.10)$ & $1.53(1.10-2.13)$ & $1.62(1.34-1.97)$ & $1.65(1.34-2.02)$ \\
\hline - Major & $1.51(0.89-2.56)$ & $1.60(0.90-2.85)$ & $3.25(2.48-4.25)$ & $3.37(2.34-4.84)$ \\
\hline \multicolumn{5}{|c|}{ Complication with eight weeks: } \\
\hline - None & 1.00 (reference) & 1.00 (reference) & 1.00 (reference) & 1.00 (reference) \\
\hline - Minor & $2.20(1.80-2.69)$ & $2.08(1.66-2.62)$ & $2.35(2.05-2.68)$ & $2.31(2.00-2.67)$ \\
\hline - Major & $4.07(2.92-5.68)$ & $4.39(3.04-6.34)$ & $5.36(4.33-6.64)$ & $5.31(4.20-6.71)$ \\
\hline \multicolumn{5}{|c|}{ Complications between eight weeks and one year: } \\
\hline - None & 1.00 (reference) & 1.00 (reference) & 1.00 (reference) & 1.00 (reference) \\
\hline - Minor & $3.21(2.56-4.01)$ & $3.17(2.47-4.08)$ & $4.53(3.93-5.22)$ & $4.52(3.87-5.28)$ \\
\hline - Major & $7.52(5.27-10.72)$ & $6.23(4.06-9.55)$ & $12.23(9.70-15.42)$ & $11.97(9.29-15.42)$ \\
\hline
\end{tabular}


- Table 5 Risk factors for unfavorable outcome of the surgery concerning self-reported perception of medical condition and satisfaction one year postoperatively. Results of logistic regression analyses with dichotomized outcome measures.

\begin{tabular}{|c|c|c|c|c|}
\hline \multirow[b]{3}{*}{ Factor } & \multicolumn{4}{|c|}{ Outcome measures } \\
\hline & \multicolumn{2}{|c|}{$\begin{array}{l}\text { Medical condition: } \\
\text { Unchanged, worse or much worse } \\
\text { (reference: improved or much improved) }\end{array}$} & \multicolumn{2}{|c|}{$\begin{array}{l}\text { Opinion about result of surgery: } \\
\text { Neither satisfied or dissatisfied } \\
\text { (reference: satisfied or very satisfied) }\end{array}$} \\
\hline & $\begin{array}{l}\text { Crude OR and } \\
95 \% \mathrm{Cl}\end{array}$ & $\begin{array}{l}\text { Adjusted OR and } \\
95 \% \mathrm{Cl}^{*}\end{array}$ & $\begin{array}{l}\text { Crude OR and } \\
95 \% \mathrm{CI}\end{array}$ & $\begin{array}{l}\text { Adjusted OR and } \\
95 \% \mathrm{Cl}^{*}\end{array}$ \\
\hline \multicolumn{5}{|l|}{ Mode of hysterectomy: } \\
\hline - Abdominal total hysterectomy & 1.00 (reference) & 1.00 (reference) & 1.00 (reference) & 1.00 (reference) \\
\hline - Abdominal subtotal hysterectomy & $0.85(0.67-1.09)$ & $0.97(0.75-1.26)$ & $0.68(0.58-0.80)$ & $0.74(0.62-0.87)$ \\
\hline - Laparoscopic total hysterectomy & $1.13(0.87-1.48)$ & $1.10(0.80-1.50)$ & $1.02(0.83-1.25)$ & $0.87(0.69-1.10)$ \\
\hline - Laparoscopic subtotal hysterectomy & $0.67(0.21-2.13)$ & $0.65(0.16-2.69)$ & $0.62(0.33-1.17)$ & $0.56(0.27-1.16)$ \\
\hline - Vaginal hysterectomy & $0.54(0.42-0.69)$ & $0.64(0.47-0.87)$ & $0.55(0.47-0.65)$ & $0.61(0.51-0.71)$ \\
\hline \multicolumn{5}{|l|}{ Indication for hysterectomy: } \\
\hline - Menstrual disorder & 1.00 (reference) & 1.00 (reference) & 1.00 (reference) & 1.00 (reference) \\
\hline - Uterine myoma & $2.47(1.99-3.05)$ & $2.33(1.82-2.98)$ & $1.34(1.14-1.56)$ & $1,22(1.03-1.45)$ \\
\hline - Pain-related & $3.15(2.53-3.91)$ & $3.29(2.57-4.22)$ & $2.38(2.06-2.74)$ & $2.17(1.85-2.55)$ \\
\hline - Other indications & $2.30(1.16-4.57)$ & $2.18(0.99-4.79)$ & $1.65(0.98-2.79)$ & $1.23(0.66-2.30)$ \\
\hline \multicolumn{5}{|l|}{ Preoperative expectation of surgery: } \\
\hline - Get rid of symptoms & 1.00 (reference) & 1.00 (reference) & 1.00 (reference) & 1.00 (reference) \\
\hline - Relieved & $1.23(0.92-1.64)$ & $1.08(0.79-1.48)$ & $1.37(1.16-1.63)$ & $1.23(1.02-1.48)$ \\
\hline - No expectations & $4.49(2.66-7.58)$ & $4.85(2.80-8.40)$ & $2.68(1.90-3.78)$ & $2.74(1.89-3.96)$ \\
\hline \multicolumn{5}{|c|}{ Remaining at least one ovary postoperatively: } \\
\hline - No & $2.01(1.52-2.65)$ & $1.26(0.90-1.76)$ & $1.79(1.47-2.18)$ & $1.29(1.02-1.62)$ \\
\hline \multicolumn{5}{|c|}{ Conversion of surgery from MIS to abdominal: } \\
\hline - Yes & $1.33(0.75-2.35)$ & $1.65(0.92-2.97)$ & $1.24(0.82-1.88)$ & $1.17(0.75-1.84)$ \\
\hline \multicolumn{5}{|l|}{ Smoking: } \\
\hline - Yes & $1.42(1.13-1.77)$ & $1.45(1.14-1.84)$ & $1.31(1.13-1.51)$ & $1.23(1.05-1.43)$ \\
\hline \multicolumn{5}{|l|}{ ASA Class: } \\
\hline - Class III/IV & $1.32(0.62-2.85)$ & $0.96(0.35-2.65)$ & $0.94(0.51-1.74)$ & $0.95(0.48-1.88)$ \\
\hline Age & $1.00(0.99-1.02)$ & $1.01(0.99-1.03)$ & $0.99(0.98-1.00)$ & $0.99(0.98-1.01)$ \\
\hline BMI & $1.00(0.98-1.02)$ & $1.01(0.99-1.03)$ & $0.99(0.98-1.01)$ & $1.00(0.98-1.01)$ \\
\hline
\end{tabular}

\section{Length of hospital stay (LOS)}

The LOS for the entire study group was mean 2.3 days (1.9 days). Occurrence of complications intraoperatively and postoperatively before discharge from hospital, and degree of complications had statistically significant impact on LOS ( $\triangleright$ Fig. $\mathbf{3} \mathbf{a}$ and $\mathbf{b}$ ). The LOS was predictive for occurrence and degree of complications reported after discharge ( $\bullet$ Fig. $\mathbf{3 c}$ and $\mathbf{d}$ ). The post hoc tests revealed that there were highly statistically significant differences in LOS $(p<0.001)$ between all three groups (complication-free, minor and major complications). The adjusted LOS was mean 2.1 days (1.6 days) for those who had no reported complications on any occasion. This was significantly lower than the mean 2.8 days $(2.1$ days) $(p<0.001)$ for those who had a complication of any degree on at least one occasion.

\section{Discussion}

The majority of women were satisfied with the result of the hysterectomy but there was an association with decreased satisfaction when complications had occurred. Pelvic pain as indication of surgery, no expectations preoperatively, and current smoking were independent risk factors for adverse outcomes in patient satisfaction. Occurrence of complications intra- and postoperatively before discharge from hospital was associated with increasing LOS. Furthermore, LOS was predictive for occurrence and degree of complications reported after discharge from hospital.

A strength of this research is the large study population, based on prospectively collected data in the GynOp. More than $75 \%$ of all benign hysterectomies performed in Sweden during the study period formed part of the register. Another strength is that exclu- 
ANCOVA, $\mathrm{p}<0.0001$

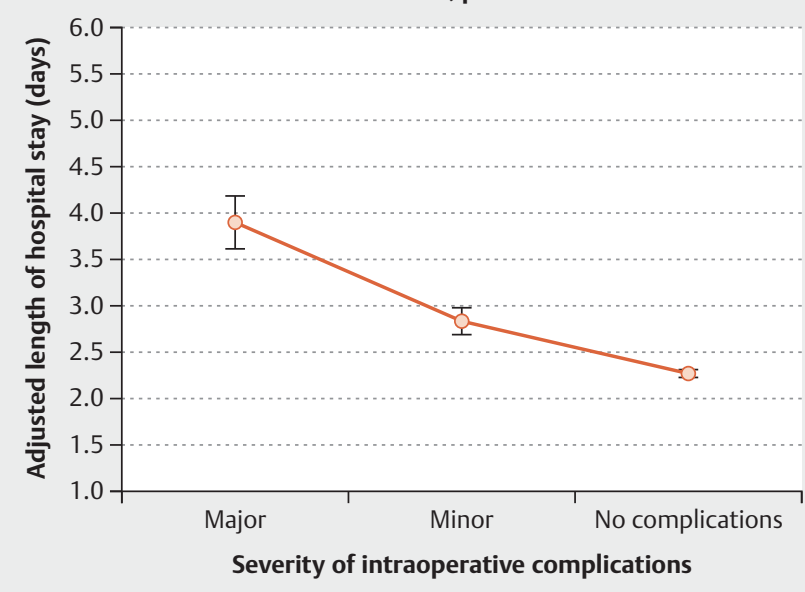

a

ANCOVA, $\mathrm{p}<0.00001$

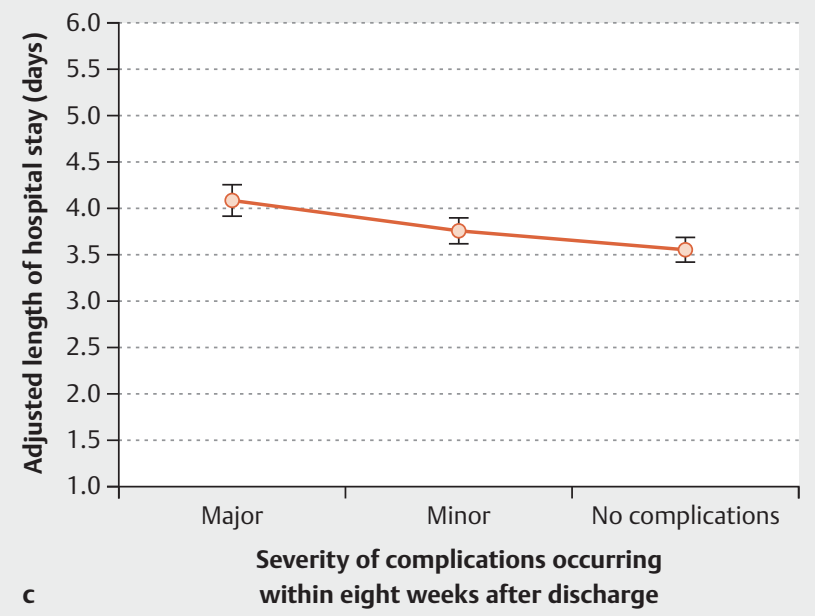

ANCOVA, $\mathrm{p}<0.0001$

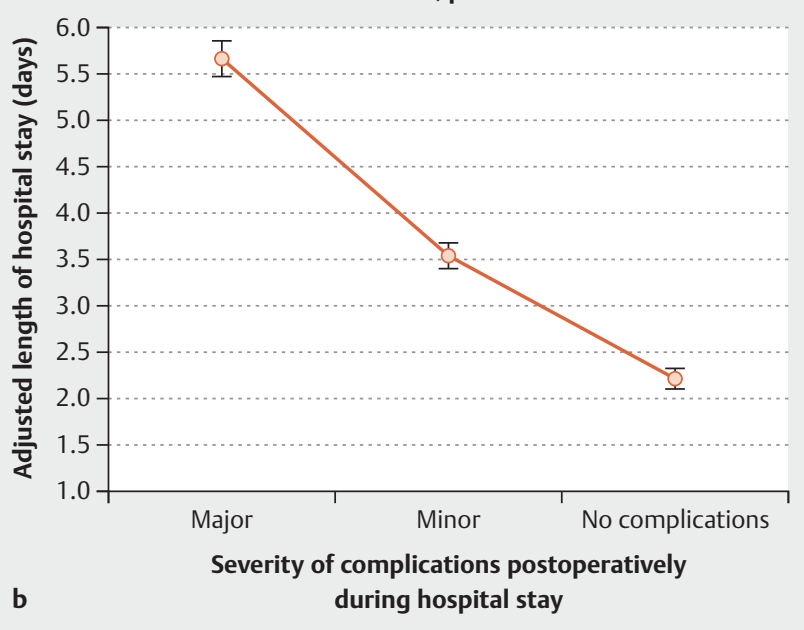

ANCOVA, $\mathrm{p}=\mathbf{0 . 0 2 4}$

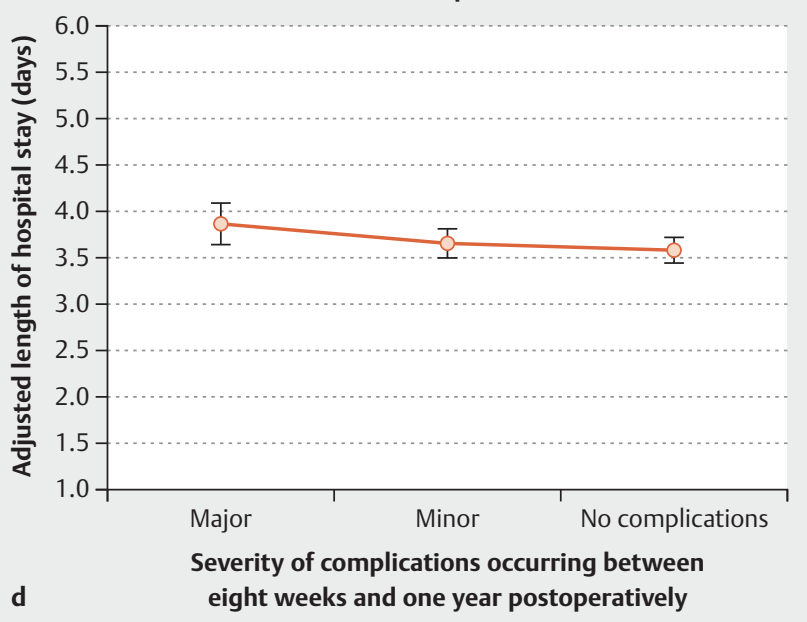

- Fig. 3 Length of hospital stay (LOS) in relation to occurrence of reported complications after hysterectomy. a Intraoperative complications. b Complications after surgery during hospital stay. LOS was also adjusted for occurrence of intraoperative complications. c Complications reported to have occurred between discharge and eight weeks postoperatively. LOS was also adjusted for complications intraoperatively and during hospital stay. $\mathbf{d}$ Complications reported to have occurred between the 8-weeks and 1-year inquiry. LOS was also adjusted for complications intraoperatively, during hospital stay and at the 8-weeks inquiry.

sion criteria were chosen to ensure that the indication of hysterectomy was most likely of uterine origin and not related to other pelvic symptoms, diseases or conditions that per se could have an impact on perceived satisfaction. However, risk of selection bias and missing data in the register represent weaknesses of the study. The interpretation of the results should be done with caution due to the inborn risk of multiple testing problems in epidemiological studies. Due to the exploratory nature of this study no statistical corrections of the p-values were done. A drawback of the study and a limitation is the lack of an overall comprehensive validation of the GynOp. However, several articles (> 50 in peer review reviewed journals) and more doctoral dissertations emanate from the register [10] which indicate that the register is consid- ered reliable, probably because of the high internal coverage of all gynecological surgery in Sweden.

Prevalence and degree of intra- and postoperative complications in relation to mode of surgery were in accordance with results of previous studies $[5,11]$. Complications, especially major, were strongly associated with less contentment with medical condition and satisfaction with surgery one year postoperatively. Moreover, pain as indication of surgery, having no or low preoperative expectations of surgery, and current smoking were above all significantly associated with adverse outcomes concerning patient-reported satisfaction. Impact of different risk factors associated with adverse outcomes in patient satisfaction following gynecological surgery have rarely been described previously. Two studies have reported that minimally invasive surgery seemed to 
be advantageous concerning patient satisfaction following hysterectomy [7, 9]. Billfeldt et al. who also used data from GynOp, excluded women who had subtotal hysterectomy in their study, although this surgical method is used in nearly $20 \%$ of all benign hysterectomies in Sweden. In the present study, abdominal subtotal hysterectomy and vaginal hysterectomy were independent factors associated with increased patient satisfaction. The explanation of a higher satisfaction rate with subtotal hysterectomy is not obvious. The choice of the surgical approach and technique are always discussed with the patient. Perhaps these patients had a preference for subtotal hysterectomy and therefore experienced a higher satisfaction due to this. On the other hand, subtotal hysterectomy causes a higher risk of persistent vaginal bleeding postoperatively, which could endanger the patient satisfaction [12]. Contrary to Billfeldt et al. who found a significantly higher satisfaction rate after laparoscopic hysterectomy than after abdominal hysterectomy, this study revealed no such advantage of the laparoscopic approach when adjusted for confounders such as complications. Billfeldt et al. presented a multivariable analysis of satisfaction rates, although not adjusted for complications that may have substantial impacts on the outcomes. Even the American study by Pitter et al. did not adjust satisfaction rates for occurrence of complications or other important confounders, although existence of complications seems to be an important significant predictor of dissatisfaction. Thus, none of these studies gave a generalizable answer to the question of satisfaction after various modes of hysterectomy [7,9].

Concerning association of pain as indication of hysterectomy with patient-reported contentment with surgery, Grundström et al. previously reported that women with pelvic pain and endometriosis were at a higher risk of being dissatisfied [5]. Brandsborg et al. stated that $32 \%$ of women reported chronic pain after hysterectomy on benign indications. Risk factors for chronic pain were preoperative pelvic pain, pain as main indication for surgery, and pain problems elsewhere preoperatively [13]. This would presumably also influence expected satisfaction with hysterectomy. The negative association between having myoma as indication for the hysterectomy and the perceived medical condition is difficult to explain. The main indication of surgery registered in the GynOp was decided by the responsible gynecologist. Menstrual disorder and pain are symptom diagnoses whereas myoma is a tentative patho-anatomical diagnosis that usually is associated with symptoms such as menstrual disorder or mechanical symptoms. The GynOp does not give norms for how to give priority to the indications. Thus there might be a mixing of symptoms and anatomical abnormalities giving the ultimate main indication. This could possibly influence the results for perceived medical condition.

The patient's preoperative expectation of surgery is probably also influenced by the preoperative information given, although evidence is lacking. It differs greatly in the beliefs and practices of healthcare professionals in the advice they give to patients $[14,15]$. Nevertheless, it seems likely that adequate and understandable patient-centered information is important in order to achieve realistic preoperative expectations $[16,17]$. Patients are more likely to be dissatisfied with result of surgery if they are not satisfied with the preoperative information $[18,19]$. The association between smoking and the negative outcomes in patient sat- isfaction after surgery as seen in this study corresponds with findings in other studies $[9,20,21]$. The reasons are speculative, but psychosocial factors may be of importance.

It has previously been suggested that LOS is adversely associated with postoperative complications $[22,23]$. To the best of our knowledge no previous study has indicated that this association seems to apply even to late appearing complications. Complications that occurred intra- and postoperatively in this study prolonged hospital stay considerably. This is an obvious drawback not only for the exposed women but also considering the deficiency of institutional care and health economics. Interestingly, LOS was even associated with the occurrence and degree of complications reported after discharge. When a major complication occurred after discharge, the LOS was on average a half day longer than for those who had a postoperative period without complications. Although a half day may be considered as clinically insignificant the association seems to indicate that something that happens during the hospital stay may predispose to complications in the postoperative period even up to one year after the surgery. The reasons for this remain speculative and merits further investigation. It therefore seems important to avoid complications not only in the immediate perioperative course but also later to achieve optimal quality of care.

\section{Conclusions}

This study showed that complications following hysterectomy were strongly associated with less contentment with surgery and an increasing LOS. Prevention of both early and late appearing complications seems to be of importance to optimize patient satisfaction. Other risk factors for adverse outcomes were pain as indication of surgery, having low or no expectations preoperatively, and current smoking. Patient-centered information to ensure realistic preoperative expectations seems essential to gain optimal satisfaction with surgery.

\section{Acknowledgements}

I am indebted to Professor Preben Kjølhede and statistician Marie Bladh, PhD for providing statistical advice and constructive criticism of the draft.

The Swedish National Quality Registry of Gynecological Surgery (GynOp), The Swedish Government and the Swedish Association of Local Authorities and Regions, which all support GynOp, are acknowledged. No specific funding was obtained.

Conflict of Interest

The authors declare that they have no conflict of interest.

References

[1] Marjoribanks J, Lethaby A, Farquhar C. Surgery versus medical therapy for heavy menstrual bleeding. Cochrane Database Syst Rev 2016; (1): CD003855

[2] van der Meij E, Emanuel MH. Hysterectomy for heavy menstrual bleeding. Womens Health (Lond) 2016; 12: 63-69

[3] Aarts JW, Nieboer TE, Johnson N et al. Surgical approach to hysterectomy for benign gynaecological disease. Cochrane Database Syst Rev 2015; (8): CD003677 
[4] Gorlero F, Lijoi D, Biamonti M et al. Hysterectomy and women satisfaction: total versus subtotal technique. Arch Gynecol Obstet 2008; 278: 405-410

[5] Grundström H, Alehagen S, Berterö C et al. Impact of Pelvic Pain and Endometriosis on Patient-Reported Outcomes and Experiences of Benign Hysterectomy: A Study from the Swedish National Register for Gynecological Surgery. J Womens Health (Larchmt) 2018; 27: 691-698

[6] Mäkinen J, Brummer T, Jalkanen J et al. Ten years of progress-improved hysterectomy outcomes in Finland 1996-2006: a longitudinal observation study. BMJ Open 2013; 3: e003169

[7] Pitter MC, Simmonds C, Seshadri-Kreaden U et al. The impact of different surgical modalities for hysterectomy on satisfaction and patient reported outcomes. Interact J Med Res 2014; 3: e11

[8] Swedish Society of Obstetrics and Gynecology. The Swedish National Quality Register for Gynecological Surgery. Online: http://www2. gynop.se/home/about-gynop/; last access: 07.07.2019

[9] Billfeldt N, Borgfeldt C, Lindkvist $\mathrm{H}$ et al. A Swedish population-based evaluation of benign hysterectomy, comparing minimally invasive and abdominal surgery. Eur J Obstet Gynecol Reprod Biol 2018; 222: 113118

[10] Swedish Society of Obstetrics and Gynecology. The Swedish National Quality Register for Gynecological Surgery. Online: http://www2. gynop.se/datauttag_forskning/publikationer/; last access: 07.07.2019

[11] Brummer TH, Jalkanen J, Fraser J et al. FINHYST, a prospective study of 5279 hysterectomies: complications and their risk factors. Hum Reprod 2011; 26: 1741-1751

[12] Borendal Wodlin N. Intraoperative cervical treatment does not affect the prevalence of vaginal bleeding 1 year postoperatively after subtotal hysterectomy. A register study from the Swedish National Register for Gynecological Surgery. Acta Obstet Gynecol Scand 2017; 96: 14301437
[13] Brandsborg B, Nikolajsen L, Hansen CT et al. Risk factors for chronic pain after hysterectomy: A nationwide questionnaire and database study. Anesthesiology 2007; 106: 1003-1012

[14] Ottesen M, Møller C, Kehlet $\mathrm{H}$ et al. Substantial variability in postoperative treatment, and convalescence recommendations following vaginal repair. A nationwide questionnaire study. Acta Obstet Gynecol Scand 2001; 80: 1062-1068

[15] Fahradyan A, El-Sabawi B, Patel KM. Understanding Patient Expectations of Lymphedema Surgery. Plast Reconstr Surg 2018; 141: 1550-1557

[16] Radosa JC, Radosa CG, Kastl C et al. Influence of the Preoperative Decision-Making Process on the Postoperative Outcome after Hysterectomy for Benign Uterine Pathologies. Geburtsh Frauenheilk 2016; 76: 383389

[17] Knudsen NI, Wernecke KD, Siedentopf F et al. Fears and Concerns of Patients with Uterine Fibroids - a Survey of 807 Women. Geburtsh Frauenheilk 2017; 77: 976-983

[18] Lieng M, Qvigstad E, Istre O et al. Long term outcomes following laparoscopic supracervical hysterectomy. BJOG 2008; 115: 1605-1610

[19] Shehmar M, Gupta JK. The influence of psychological factors on recovery from hysterectomy. J R Soc Med 2010; 103: 56-59

[20] Lashen H, Jones GL, Duru C et al. Bowel dysfunction after total abdominal hysterectomy for benign conditions: a prospective longitudinal study. Eur J Gastroenterol Hepatol 2013; 25: 1217-1222

[21] Forsgren C, Altman D. Risk of pelvic organ fistula in patients undergoing hysterectomy. Curr Opin Obstet Gynecol 2010; 22: 404-407

[22] Kjølhede P, Halili S, Löfgren M. The influence of preoperative vaginal cleansing on postoperative infectious morbidity in abdominal total hysterectomy for benign indications. Acta Obstet Gynecol Scand 2009; 88: 408-416

[23] Vonlanthen R, Slankamenac K, Breitenstein S et al. The impact of complications on costs of major surgical procedures: a cost analysis of 1200 patients. Ann Surg 2011; 254: 907-913 